\title{
Correlates of Employee Compensation and Commitment
}

\author{
*Dr. R.Alamelu \\ ${ }^{*}$ Dr. S.T.Surulivel \\ \#Dr.L.Cresenta Shakila Motha \\ *Dr. R.Amudha \\ ${ }^{*}$ Dr. S.Selvabaskar
}

*Faculty Members, School of Management, SASTRA University, Thanjavur

\#Faculty Member, Training and Placement, SASTRA University, Thanjavur

alamelu@mba.sastra.edu,drsts@sastra.edu,cresenta@sastra.edu, amudha@mba.sastra.edu,selvabaskar@mba.sastra.edu

Doi:10.5901/mjss.2015.v6n5p335

\section{Abstract}

In recent days, employees are considered as an important asset of an organisation and their commitment plays a vital role in achieving sustainable growth of the organisation. The employee commitment always plays a very predominant role in achieving the vision and mission of the organisation. The employee commitment was identified as a baseline for the performance of the company. This commitment is said to have a relationship with the compensation what employee receives. It is predicted that employee commitment may be increased when the employee are satisfied by the elements of compensation. Hence the researcher focuses on the relationship between compensation and commitment, factors of compensation affecting employee commitment, and identifies the employee's perception towards the components of pay model. The researcher has conducted the study with 300 samples collected from small manufacturing industries in Tiruchirappalli District, Tamil Nadu, India. Researcher has applied tools like ANOVA, Chi-square test, Structural Equation Modelling for the purpose of analysing the relationship between employee compensation and their commitment. The study outcome revealed that employee commitment was strongly associated with the satisfaction of employees towards their compensation based on pay model.

Keywords: Compensation, Employee Commitment, Pay structure, Incentives, Internal alignment

\section{Introduction}

Employee commitment means employee's psychological and physical engagement at their work. Employee commitment plays a very predominant role in achieving the goals of the company within the predetermined period. Nowadays in the competitive world, as many manufacturing industry are going for alliances and the work stress of the employee also said to be increases, this may affect the commitment of the employee. Thus commitment of the employee is influenced by various factors like organisational culture, critical success factors, standards and benefits. And also compensation is identified as one such important factor. The term compensation means any form of payment made to an individual for the work done for the organisation or any form of service rendered to the company. Hence when the employee is satisfied with appropriate type of compensation, their commitment may be increased or maintained. Hence the executive must design the compensation structure based on the employee needs to obtain their commitment for the organisation.

Hence this present study focuses on the relationship between compensation and commitment, the factors of compensation affecting commitment, to study the level of commitment the employee have in their job and to suggest some ideas for better compensation system that increases the employee commitment.

\section{Review of Literature}

Adeline kuznia (2008) analyzed the requirements of service to the human industry by forming a good compensation system that attract and retain employees who are talented and qualified. Multiple streams of research have shown that the amount of pay an employee receives strongly influences key attitudes and behaviours including job satisfaction, organizational commitment, and job performance (Bloom \& Michel, 2002; Greenberg, 1990; Lazear \& Rosen, 1981). The 
level of pay also impacts an individual's feelings of self-worth and the perception of their value to the organization and plays an instrumental role in the formation of behavioural intentions such as desire to leave an organization (Mowday et al., 1982). It is important to identify the relationship of employees' commitment and their compensation for the following a few reasons. First, employee organizational commitment is regarded as a multi-dimensional construct (Mowday et al., 1982). Second, compensation is an important issue for both employers and employees. Compensation is a broad and complex issue. Compensation policies must be developed and administered by all organizations regardless of size (Milkovich and Newman, 2005).

Amani khaled bouresli (2001) examined the link between the benefits that is given as a result of newly formed pay model and change in the working performance following the IPO event. A pair of hypotheses was used to analyze the relations among three important variable ,compensation structure, firm operating performance, and corporate governance and these variables where analyzed. The outcome of the research was higher the compensation higher the employee commitment and performance .Carl $\mathrm{m}$. kinnoin (2005) examined the connection between the policies that are required by the workman and three elements like job satisfaction, intent to leave, and employee commitment. The survey was taken from student of graduation or under graduation in university of California and who are working along with their education. The finding was concluded as there is a connection among job commitment and friendly policies. carolyn a. stephenson (2012) examined the viewpoint towards certain elements that are to be taken into account in formulating the performance based compensation. Samples were collected from 444 schools and their respective principles in 178 district of Colorado State. The author determined the final result as the execution based pay model system is strongly accepted.

Diane ferry coble (2004) examined the workers dedication in combination with some factors of organization. The factor by which the employee is committed differs according to the organizational climate, working members and their job designation. The researcher concluded that the commitment varies according to the organizational climate, designation and compensation. Marcia m. bennett, (2001) examined the compensation structure of six medical schools at Midwestern United states. 1320 questioners were given; teachers were given 1200 questioners and 120 to the superintendents. The finding of the research indicates that there was change in teacher's time commitment, quality of engagement in teaching, research, caring, and service due to change in pay model. Mark evan bryant (2001) indicated the importance of discovering workers commitment using various factors. The research was conducted with one hundred and ten people from popular manufacturing company. Satisfaction and citizenship activities are the key elements to discover workers commitment are the finding of the study. Meyer and allen $(1991,1997)$ indicated the Three-Component factor (TCM) of commitment consists of affective commitment (AC), continuous commitment (CC), and normative commitment (NC). The three factors were examined with the workers of law. The survey was conducted with 200 employees. Multiple correlations were carried on the collected samples. And it was concluded that employee commitment has connection with organization culture and compensation.

\section{Objectives of the Study}

- To identify the employees perception towards the components of pay model.

- To understand the level of employee commitment towards their job.

- To ascertain the relationship between employee compensation and employee commitment.

- To offer suitable suggestion to improve employee commitment at par with the present compensation system

\section{Methodology}

Employee compensation showing a predominant role and employee commitment is acting as a bond to create a healthy employment relationship with in the organisation which leads to better organization performance. Hence the current study proposed to find out the relationship between employee compensation based on pay model and their commitment towards job. To identify the same, the present study is based on descriptive analysis. The objective of the study and the hypothesis is studied with the help of the primary data that has been collected. A well reviewed structured questionnaire was used to collect the primary data. The primary data were collected for a period of one month from 10th March 2014 to 10 April 2014.

\subsection{Sample Design}

The sample has been collected from small manufacturing units in Trichy District. 
The interview schedule was administered personally by the researcher to the employees and simple random sampling method was used to collect 300 samples from the employee.

The internal consistency of the given questionnaire is determined using Cronbach's Alpha. And it is shown below in the table 1 . The alpha coefficient for all the 33 items is .800 which means the the item have relatively good internal consistency.

Table 1. Reliability Statistics

\begin{tabular}{|c|c|}
\hline Cronbach's Alpha & No of Items \\
\hline .800 & 33 \\
\hline
\end{tabular}

\subsection{Tools applied for analysis}

The techniques adapted for the analysis of results are Chi-square test, Frequency analysis, ANOVA, and SEM.

\section{Analysis And Interpretation}

\subsection{Demographic Characteristics}

Table 2 represents the demographic features of the respondents.

Table 2. Distribution of respondents on the basis of demographic factors:

\begin{tabular}{|l|c|c|}
\hline Demographic variables & Categories & Percentage of the respondents \\
\hline \multirow{3}{*}{ Gender } & Male & 60 \\
\cline { 2 - 3 } & Female & 31 \\
\hline \multirow{4}{*}{ Age } & $18-20$ & 27 \\
\cline { 2 - 3 } & $21-25$ & 50 \\
\cline { 2 - 3 } & $26-30$ & 20 \\
\cline { 2 - 3 } & Above 30 & 3 \\
\hline \multirow{3}{*}{ Educatignation } & Officers & 30 \\
\cline { 2 - 3 } & workers & 70 \\
\hline \multirow{4}{*}{ Salary } & Diploma & 66 \\
\cline { 2 - 3 } & Ug & 29 \\
\cline { 2 - 3 } & Pg & 5 \\
\hline \multirow{3}{*}{ Experience } & $1000-3000$ & 10 \\
\cline { 2 - 3 } & $4000-6000$ & 39 \\
\cline { 2 - 3 } & $7000-10000$ & 46 \\
\cline { 2 - 3 } & Above 10000 & 5 \\
\cline { 2 - 3 } & 1 & 23 \\
\cline { 2 - 3 } & $2-5$ & 65 \\
\hline
\end{tabular}

About $60 \%$ of the respondents are male and $31 \%$ female. Majority of the employee i.e. $50 \%$ of the employee belong to age group of $21-25$.only $3 \%$ of the respondents are above 30 years. $27 \%$ of the respondents belong to the age group of range 18-20 years. When considering the salary only $5 \%$ of the employees are receiving above 10000 and major group of respondents are receiving salary of range 7000-10000. On taking the experience into account $65 \%$ of the respondents are having an experience of 2 to 5 years.

For better understanding and identification, main objective wise analysis and interpretation has been done.

Objective 1: To identify the employee's perception towards the components of pay model.

In order to identify the employees perception towards the components of pay model. ANOVA has been used as a tool to analyse the study.

$\mathrm{H} 0=$ There is no significant relation between age and components of pay model.

$\mathrm{H} 0=$ There is no significant relationship between gender and components of pay model.

$\mathrm{H} 0=$ There is no significant relationship between designation and components of pay model 
$\mathrm{HO}=$ There is no significant relationship between experience of an employee and components of pay model.

Table 3. Relation Between Demographic Variable And Factors Of Compensation

\begin{tabular}{|l|c|c|}
\hline Factors & P Value & Resultant Inference \\
\hline \multicolumn{3}{|c|}{ Age } \\
\hline Pay structure & 0.268 & H0 accepted \\
\hline Incentive program & 0.197 & H0 accepted \\
\hline Evaluation & 0.511 & H0 accepted \\
\hline Internal structure & 0.345 & H0 accepted \\
\hline
\end{tabular}

\begin{tabular}{|l|c|c|}
\hline \multicolumn{3}{|c|}{ Gender } \\
\hline Pay structure & 0.303 & H0 accepted \\
\hline Incentive Program & 0.170 & H0 accepted \\
\hline Evaluation & 0.984 & H0 accepted \\
\hline Internal Structure & 0.926 & H0 accepted \\
\hline \multicolumn{2}{|c|}{ Designation } \\
\hline
\end{tabular}

\begin{tabular}{|l|c|c|}
\hline Pay structure & 0.009 & H0 rejected \\
\hline Incentive Program & 0.047 & H0 rejected \\
\hline Evaluation & 0.556 & H0 accepted \\
\hline Internal Structure & 0.363 & H0 accepted \\
\hline \multicolumn{2}{|c|}{ Experience } \\
\hline Pay structure & 0.212 & H0 accepted \\
\hline Incentive Program & 0.794 & $\mathrm{H} 0$ accepted \\
\hline Evaluation & 0.979 & $\mathrm{H} 0$ accepted \\
\hline Internal Structure & 0.343 & $\mathrm{H} 0$ accepted \\
\hline
\end{tabular}

( $5 \%$ level of significance)

Table 3 clearly states that the null hypothesis is rejected for demographic variable designation and pay model components like pay structure and incentive program. Thus there exist a relationship between designation and two components of pay model i.e. pay structure and incentive program. And the null hypothesis is accepted for all other demographic variables and components of pay model which describes irrespective of all demographic variables there is no relationship and pay model components.

Objective 2: To understand the level of employee commitment towards their job.

In order to determine the level of commitment chi-square test has been used as a tool to analyses the study.

$\mathrm{H} 0=$ There is no significant relationship between gender and level of commitment.

$\mathrm{H} 0=$ There is no significant relationship between age and level of commitment.

$\mathrm{HO}=$ There is no significant relationship between designation and level of commitment.

$\mathrm{H} 0=$ There is no significant relationship between experience and level of commitment.

Table 4. Relation between Demographic Variable and Level of Commitment

\begin{tabular}{|c|c|c|c|}
\hline Factors & Chi-square value $x^{2}$ & Significance value & Resultant Inference \\
\hline \multicolumn{4}{|c|}{ Affective Commitment } \\
\hline Gender & 7.526 & .111 & H0 accepted \\
\hline Age & 11.029 & .526 & HO accepted \\
\hline Designation & 1.466 & .833 & HO accepted \\
\hline Experience & 19.011 & .015 & H0 accepted \\
\hline \multicolumn{4}{|c|}{ Continuous Commitment } \\
\hline Gender & 4.293 & .368 & HO accepted \\
\hline Age & 7.173 & .846 & HO accepted \\
\hline Designation & 13.348 & .010 & $\mathrm{H} 0$ rejected \\
\hline Experience & 21.414 & .006 & HO rejected \\
\hline \multicolumn{4}{|c|}{ Normative Commitment } \\
\hline Gender & 2.474 & .649 & H0 accepted \\
\hline
\end{tabular}




\begin{tabular}{|l|c|c|c|}
\hline Age & 13.816 & .313 & H0 accepted \\
\hline Designation & 5.775 & .217 & H0 accepted \\
\hline Experience & 5.223 & .733 & H0 accepted \\
\hline
\end{tabular}

(5\% level of significance)

Table 4 clearly states that the null hypothesis is rejected for continuous level of commitment with their demographic variable designation and experience. Thus there exist a relationship between continuous level of commitment and the demographic variables i.e. designation and experience. And the null hypothesis is accepted for other level of commitment i.e. normative commitment and affective commitment with the demographic variables like age, gender, designation and experience.

Objective 3: To ascertain the relationship between employee compensation and employee commitment

Employee commitment is a significant factor for the organization to achieve organizational objectives. This employee commitment and compensation is said to have a relationship with each other. It is expected that employee commitment may increase when the factors of compensation expected by the employee are satisfied. Thus increasing or maintaining the employee commitment with respect to compensation is one of the challenging factors for the management. To identify the same, SEM was performed to analyze the fitness of the model based upon the factors considered for the present study. For the purpose of assessing the relationship between the components of pay model and employee commitment, the importance was given to Chi-square/degrees of freedom ( $\mathrm{x} 2 / \mathrm{df})$. Table 6 shows the values of $\mathrm{CFI}, \mathrm{GFI}, \mathrm{AGFI}, \mathrm{RMR}$, and RMSEA.

Table 5. Variables in the Structural Equation Model Analysis

\begin{tabular}{|l|l|l|c|c|c|c|c|}
\hline Variables & Unstandardised co-efficient & S.E & Standardised co-efficent & t value. & P value \\
\hline Employee satisfaction & $<---$ & Performance evaluation & .043 & .104 & .415 & 3.39 & .048 \\
\hline Employee satisfaction & $<---$ & Internal structure alignment & .126 & .113 & 1.117 & 3.24 & .024 \\
\hline Employee satisfaction & $<---$ & Incentive Programmes & .189 & .120 & 1.571 & 3.22 & .016 \\
\hline Employee satisfaction & $<---$ & Competitive pay structure & .178 & .110 & 1.624 & 3.26 & .014 \\
\hline Employee Commitment & $<---$ & Employee satisfaction & .008 & .079 & .102 & 1.32 & .028 \\
\hline
\end{tabular}

Here the coefficient of performance evaluation is 0.043 represents the partial effect on internal structure alignment, incentive programmes, competitive pay structure and employee satisfaction as constant. The estimated positive sign implies that such effect is positive that employee satisfaction towards compensation would increase by every unit increase in performance evaluation and this coefficient value is significant at $5 \%$ level. The coefficient of internal structure alignment is 0.126 represents the partial effect on performance evaluation, incentive programmes, competitive pay structure and employee satisfaction as constant. The estimated positive sign implies that such effect is positive that employee satisfaction towards compensation would increase by every unit increase in internal structure alignment and this coefficient value is significant at $5 \%$ level. The coefficient of incentive programme is 0.189 represents the partial effect on performance evaluation, internal structure alignment, competitive pay structure and employee satisfaction as constant. The estimated positive sign implies that such effect is positive that employee satisfaction towards compensation would increase by every unit increase in employee incentive program and this coefficient value is significant at $5 \%$ level. The coefficient of competitive pay structure is 0.108 represents the partial effect on performance evaluation, internal structure alignment, incentive programmes and employee satisfaction as constant. The estimated positive sign implies that such effect is positive that employee satisfaction towards compensation would increase by every unit increase in existing compensation pay structure and this coefficient value is significant at $5 \%$ level. The coefficient of employee satisfaction towards compensation is 0.008 represents the partial effect on performance evaluation, internal structure alignment, incentive programmes, and competitive pay structure as constant. The estimated positive sign implies that such effect is positive that employee satisfaction towards compensation would increase by every unit increase in employee commitment and this coefficient value is significant at $5 \%$ level.

Model Fit Summary

\begin{tabular}{|l|c|l|}
\hline Variable & Value & Suggested Values \\
\hline Chi-square value & $4.559(0.472)$ & P-value $>.05$ \\
\hline GFI & 0.999 & $>0.90$ (Hair et al,. 2006) \\
\hline AGFI & 0.993 & $>0.90$ (Daire Hooper et al. 2008) \\
\hline CFI & 1.000 & $>0.90$ (Hu and Bentler, 1999) \\
\hline
\end{tabular}




\begin{tabular}{|l|l|l|}
\hline & & \\
\hline RMR & 0.000 & $<0.10$ ( Hair et al.,2006) \\
\hline RMSEA & 0.000 & $<0.08$ (Hair et al., 2006) \\
\hline
\end{tabular}

As per the result, it is found that the calculated $P$ value is 0.472 which is greater than 0.05 which indicates a perfect fit of the model. The criterion for an acceptable model propounded by Gerbing and Anderson (1992): RMSEA $\leq 0.08$; CFI $\geq$ 0.90; and NFI $\geq 0.90$. According to Hu and Bentler, (1999) Chi-square goodness-to-fit (GFI) can be used to test the fit between the collected data and the projected measurement model, whether the fit is good or not depends on the probability value is greater than or equal to 0.9 . As per table 5 , the GFI of this study is 0.999 , which is higher than the recommended value of 0.90 the other measures also fitted satisfactorily; AGFI $0.993, C F I=1.000$, and RMSEA $=0.00$ with $\mathrm{X} 2 / \mathrm{df}=0.69$ less than 3 (Bagozzi and Yi, 1988) indicate a good absolute fit of the model. Structural model can be accepted since goodness of fit indices support the model fit.

\section{Discussion and Conclusion}

Out of the total respondents $50 \%$ of respondents belong to the age group $21-25 y e a r s .27 \%$ belong to the age group 1820 years. $20 \%$ belong to the age group of $26-30.69 \%$ are male and $31 \%$ are female. $90 \%$ of the respondents are workers. $30 \%$ of respondents are officers.66\% of respondents have finished diploma. $29 \%$ of respondents have finished UG. $5 \%$ of respondents have finished PG.6\% of the respondents are receiving salary of range $7000-10000.39 \%$ of respondents are receiving salary of range $4000-6000.10 \%$ of the respondents are receiving salary of range $1000-3000$. And $5 \%$ of the respondents receive salary above 10000 .

The ANOVA result shows that there exists a significant difference between designation of the employee and pay structure component and incentive program. And the Chi-square test reveals that a significant relationship occurs between continuous commitment on designation and experience. Hence the company can maintain or increase the level of commitment by taking continuous survey of the pay model with the existing companies of the same industry and can benchmark the best pay model for the employee. The management can increase the formal policies and procedures that reduce employee stress and facilitate greater employee commitment. The employer should see that these policies are implemented and not abused by the employee. The management can also implement HR accounting system to identify the cost over the employees so that they are paid appropriately for their designation and experience. And this helps in increasing the commitment of the employee. A change in compensation affects change in performance hence compensation based on the performance on their job description can be followed to increase the commitment. The affective commitment of the employees can be enhanced by following family friendly policies like children education, medical allowance for the family etc. Apart from monetatory compensation the management can also provide good working environment, increase clarity and effectiveness in communication, increase sense of responsibility and ownership, and increase opportunities for personnel growth and this may increase normative commitment of the employee.

The SEM analysis helps to understand the relationship between employee satisfaction towards compensation and their commitment and also to determine the factors of pay model effecting employee commitment towards their job. The term compensation means any form of payment made to an individual for the work done for the organisation. Hence the compensation acts as a medium that enhances the commitment of the employee in their work and creates a strong sense of belongingness to their organisation. The commitment of the employee is an important factor through which the vision and mission of the organisation can be achieved at predetermined period. It is the responsibility of the company to analyse the factors of pay model that has to be enhanced along with non monetatory factors to drive employee commitment. The pay structure followed by the company is said to be effective as it has a positive impact on commitment. Hence by using benchmark techniques and improving communication, formal policies and procedures the company can further enhance the level of commitment. This paper helps to study the relationship between various components of pay model with employee commitment. In future the same study may be conducted for service providing organisation to improve the employee commitment and improving business excellence.

\section{References}

Bloom, M., \& John G. Michel (2002). The relationships among organizational context, pay dispersion, and managerial turnover. Academy of Management Journal, 45: 33-42.

Bouresli, Amani Khaled. (2001) Managerial incentives and firm performance :evidence from initial public offerings 
Employee intentions to participate in change. http:/www.d.scholar.cnkl.net/detail/Date of access:11/04/2015

Greenburg, J. (1990). Organizational justice: Yesterday, today, and tomorrow. Journal of Management, 16: 399-432.

Kinnoin, Carl, M. (2005). "An examination of the relationship between familyfriendly policies and employee job satisfaction, intention to leave and organization commitment, Nova Southeastern University. 2290.

Kuznia, A. (2008). Designing a variable compensation plan for direct support professionals in the field of developmental disabilities (Order No. 1464877). Available from ProQuest Dissertations \& Theses Global. (304368097). Retrieved from http://search.proquest.com/docview/304368097?accountid=31785

Lazear, E. \& Rosen, S. (1981). Rank order tournaments as optimum labor contracts. Journal of Political Economy, 89: 841-864.

Marcia M. Bbennett, (2001) https://books.google.co.in/books?id=5ZhBuAAACAAJ. Alterations to Faculty Compensation Structures at Midwest Medical Schools.

Meyer, Brent A.,(2013), A study of the relationship between engagement of multigenerational public sector workers and the incentive compensation motivator factor, P-119.

Milkovich, G. T., \& Newman, J. M. 1996. Compensation 8th ed. Chicago: Irwin.

Mowday, R.T., Porter, LW. and Steers, R.M. (1982), Employee Organizational Linkages Academy Press, New York.

Stephenson, Carolyn.A (2012).School principals' attitudes towards performance based compensation, Available from ProQuest Dissertations \& Theses Global. (1023815180). Retrieved from http://search.proquest.com/docview/1023815180?accountid=3178 52012,P-103

The Nature of Employee Commitment: Exploring the Value of the Multidimensional Perspective North Carolina State University., 2001 https://books.google.co.in/books?id=zZWFNwAACAAJ

Annexure: SEM-Employee Compensation and Commitment

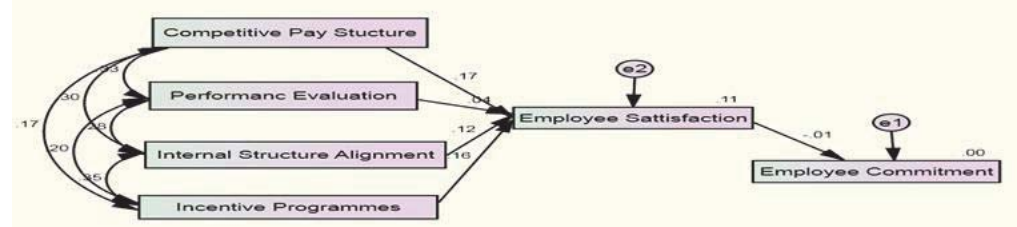

